(c) American Dairy Science Association, 2006.

\title{
Deferoxamine Reduces Tissue Damage During Endotoxin-Induced Mastitis in Dairy Cows ${ }^{1}$
}

\author{
K. Lauzon, ${ }^{\star} \dagger X$. Zhao, $†$ and P. Lacasse ${ }^{\star 2}$ \\ *Dairy and Swine Research and Development Centre, Agriculture and Agri-Food Canada, PO Box 90 STN Lennoxville, 2000 College Street, \\ Sherbrooke, Quebec, Canada J1M 1 Z3 \\ †Department of Animal Science, McGill University, 21111 Lakeshore Road, Sainte-Anne-de-Bellevue, Quebec, Canada H9X 3V9
}

\section{ABSTRACT}

The protective effects of 3 antioxidants on polymorphonuclear neutrophil-induced damage to mammary cells were evaluated in vivo using an endotoxin-induced mastitis model. Fifteen healthy, midlactation cows with no history of clinical Escherichia coli mastitis were randomly assigned to 1 of the 3 treatment groups corresponding to each modulator to be evaluated, that is, deferoxamine, catechin, and glutathione ethyl ester. Each cow had 1 quarter infused with saline and 1 quarter infused with the selected modulator; a third quarter was infused with lipopolysaccharides (LPS), whereas the fourth quarter received a combination of LPS and the modulator. Infusion of LPS caused acute mastitis as determined by visual observations and by large increases in milk somatic cell count, BSA, and proteolytic activity. These parameters were not affected by antioxidant administration. The extent of cell damage was evaluated by measuring milk levels of lactate dehydrogenase and $N$-acetyl- $\beta$-D-glucosaminidase activity. Levels of these parameters were several times higher after LPS administration. Intramammary infusions of catechin or glutathione ethyl ester did not exert any protective effect, whereas infusion of deferoxamine, a chelator of iron, decreased milk lactate dehydrogenase and NAGase activity, suggesting a protective effect against neutrophil-induced damage. The protective effect of deferoxamine was also evidenced by a lower milk level of haptoglobin. The proteolytic activity of mastitic milk was not influenced by the presence of deferoxamine. Overall, our results suggest that local infusion of deferoxamine may be an effective tool to protect mammary tissue against neutrophil-induced oxidative stress during bovine mastitis.

Key words: mammary gland, antioxidant, reactive oxygen species, protease

\footnotetext{
Received February 14, 2006.

Accepted April 25, 2006.

${ }^{1}$ Dairy and Swine Research and Development Centre contribution no. 896.

${ }^{2}$ Corresponding author: lacassep@agr.gc.ca
}

\section{INTRODUCTION}

Mastitis is an inflammatory reaction that usually occurs following an IMI. The inflammatory response involves the massive transmigration of polymorphonuclear neutrophils (PMN) from the blood into the mammary gland (Paape et al., 2000). The presence of functional neutrophils is known to be crucial to host defense against bacterial pathogens (Kehrli et al., 1990). This was also previously demonstrated by Schalm et al. (1976), who showed that treating cows with an antibovine leukocyte serum could turn chronic Staphylococcus aureus mastitis into a gangrenous disease. The main functions of PMN are to engulf pathogens and destroy them via a variety of bactericidal mechanisms. Indeed, PMN contain intracellular granules that contain bactericidal peptides, proteins, and enzymes such as elastase and other proteinases and myeloperoxidase that are released into phagocytic vacuoles or the extracellular environment (Borregaard et al., 1993). Additionally, activated PMN have recently been found to release granule proteins and chromatin that together form extracellular fibers. These extracellular traps bind microorganisms and ensure a high local concentration of antimicrobial agents to degrade virulence factors and kill bacteria (Brinkmann et al., 2004). The other mechanism by which PMN eliminates bacteria is oxygen dependent and produces toxic reactive oxygen species (ROS). The cornerstone of this process is the generation of superoxide $\left(\mathrm{O}_{2}{ }^{-}\right)$via the enzyme NADPH-oxidase. The superoxide further reacts to yield other toxic ROS such as hydrogen peroxide $\left(\mathrm{H}_{2} \mathrm{O}_{2}\right)$, hydroxyl radical $\left(\mathrm{OH}^{*}\right)$, and hypochlorous acid $(\mathrm{HOCl})$.

In several studies on inflammation, the oxidants and proteases released by PMN have been associated with tissue damage (Weiss, 1989; van Asbeck, 1990; Mehrzad et al., 2005). Oxidative stress can cause damage to all types of biomolecules (DNA, proteins, lipids, and carbohydrates) and therefore induce tissue injury. In cases of acute coliform mastitis, the amount of ROS released by PMN may overwhelm the cow's endogenous antioxidant protection mechanisms and therefore add to the inflammation, causing extensive tissue damage 
that invariably causes losses in milk production and may lead to complete loss of the quarter. For that reason, antioxidants could be used as therapeutic agents to neutralize the effect of an overproduction of ROS. The protective effects of various antioxidants against the cytotoxic effects of ROS have been demonstrated in diverse human diseases both in vitro (Richter-Landsberg and Vollgraf, 1998) and in vivo, as reviewed by Halliwell and Gutteridge (1999).

The involvement of PMN extracellular ROS (Capuco et al., 1986) and pro-ROS cytokines (Shuster et al., 1996) in mammary tissue damage during mastitis has been demonstrated. In vitro, activated blood PMN have been shown to be cytotoxic for mammary epithelial cells (Ledbetter et al., 2001; Lauzon et al., 2005), possibly via the release of extracellular ROS such as hydroxyl radicals (Boulanger et al., 2002). Additionally, we demonstrated that the addition of exogenous deferoxamine (DFO), catechin, or glutathione ethyl ester (GEE) was able to prevent damage caused by phorbol-12-myristate-13-acetate-activated PMN to mammary cells in culture (Lauzon et al., 2005). Therefore, we hypothesized that the use of these antioxidants in our in vivo study may lower the oxidative stress experienced by the mammary cells and accelerate cellular recovery.

Intramammary infusion of LPS is often used to study events occurring during Escherichia coli mastitis because it mimics the symptoms of naturally occurring mastitis without microorganism development and toxin production that could cause direct damaging effects on the mammary epithelial cells (Oliver and Calvinho, 1995). In lesions associated with acute inflammation, bacterial endotoxins damage tissue either directly or by attracting PMN that, in turn, release damaging substances (Birkedal-Hansen, 1993). In this study, an endotoxin-induced model of mastitis was used to evaluate the protective effects of intramammary infusion of catechin, DFO, or GEE on PMN-induced epithelial mammary damages.

\section{MATERIALS AND METHODS}

\section{Chemicals and Reagents}

Unless specified, all reagents used were purchased from Sigma Chemical Co. (St. Louis, MO). Lipopolysaccharide (E. coli O55:B5), DFO, and GEE were dissolved in sterile saline. Catechin was dissolved in $100 \%$ ethanol before being further diluted in saline. The acrylamide-bis-acrylamide solution, ammonium persulfate, $N, N, N^{\prime}, N^{\prime}$ - tetramethylethylenediamide, Kaleidoscope prestained standards, and Coomassie Brilliant Blue R250 were from Bio-Rad Laboratories (Hercules, CA).

\section{Animals and Experimental Procedures}

The experiments were conducted in accordance with the guidelines of the Canadian Council on Animal Care. Fifteen healthy, high-yielding Holstein cows in midlactation with no history of clinical $E$. coli mastitis were used. Only cows with bacteriologically negative milk samples and a milk SCC of less than $2 \times 10^{5}$ cells $/ \mathrm{mL}$ of milk per individual quarter were used in the study. The cows were randomly assigned to 1 of the 3 treatment groups (5 cows per group) corresponding to each modulator evaluated, that is, DFO, catechin, and GEE. Each individual mammary quarter was designated as an experimental unit. For each modulator selected, 5 cows had their left front quarter injected with $20 \mathrm{~mL}$ of saline, whereas the right front quarter was injected with $20 \mathrm{~mL}$ of the selected modulator. Both front quarters served as controls for the rear quarters. Hence, the left rear quarter of each cow was injected with $500 \mu \mathrm{g}$ of LPS (E. coli O55:B5) in $20 \mathrm{~mL}$ of saline, whereas the right rear quarter was injected with $500 \mu \mathrm{g}$ of LPS in $10 \mathrm{~mL}$ of saline plus $10 \mathrm{~mL}$ of the modulator. These injections were performed immediately after morning milking. The intramammary doses of DFO, catechin, and GEE were 500, 50, and $50 \mathrm{mg}$ per injection, respectively. All solutions to be injected were prepared aseptically and were fresh. Injection of modulators was carried out immediately after the LPS challenge and was repeated at postchallenge hours (PCH) 4, 12, and 24 . Milk production data and milk samples for each quarter were collected on $\mathrm{d}-7,-4,-1$, and 0 (immediately before the LPS challenge) and at PCH 12, 24, 36, 48, 60, and 72 using individual quarter milking units. Additional milk samples were collected by hand at PCH 3 and 6 . Rectal temperature, visual observations of udder inflammation (redness and swelling), and milk appearance were also recorded, following the same schedule, by 2 observers who were unaware of the treatments that had been given. For a reason unrelated to the experiment, 1 cow assigned to the DFO group had to be removed during the experimental period, leaving only 4 cows in this treatment group.

\section{Milk Sample Processing}

Following milking, aliquots of quarter milk samples were sent to a commercial laboratory (Program d'Analyze des Troupeaux Laitiers du Québec, Sainte-Annede-Bellevue, Quebec, Canada) for determination of SCC and infrared evaluation of lactose content and protein content. The remaining quarter milk samples were centrifuged for $15 \mathrm{~min}$ at $1,000 \times g\left(4^{\circ} \mathrm{C}\right)$ before being defatted and frozen in small aliquots. To obtain whey, a part of the defatted milk was ultracentrifuged $(100,000 \times g)$ at $4^{\circ} \mathrm{C}$ for $20 \mathrm{~min}$, and the aliquots were stored at $-20^{\circ} \mathrm{C}$. 
Milk samples from each quarter were analyzed for various parameters as described below to evaluate the effect of each antioxidant on various inflammation and mastitis markers.

\section{Evaluation of Milk BSA Content}

Bovine serum albumin concentrations in the quarter milk samples were determined in triplicate as described by Bouchard et al. (1999), with some modifications. Briefly, $10 \mu \mathrm{L}$ of skim milk (samples to be analyzed) or BSA standard was mixed with $500 \mu \mathrm{L}$ of water and 500 $\mu \mathrm{L}$ of bromocresol green working solution (mixture of 1 vol of $1.2 \mathrm{~m} M$ bromocresol green dissolved in $5 \mathrm{~m} M$ $\mathrm{NaOH}$ with 3 vol of $0.2 M$ succinic acid, $\mathrm{pH} 4.0$, with Brij-35 added to a final concentration of $0.8 \%$, vol $/ \mathrm{vol}$ ). The tubes were then centrifuged at room temperature for $15 \mathrm{~min}$ at 2,500 $\times \mathrm{g}$ to pellet the $\mathrm{CN}$. Subsequently, $150 \mu \mathrm{L}$ of supernatant was transferred to 96-well plates, and absorbance was measured at $640 \mathrm{~nm}$. Bovine serum albumin concentrations in the milk samples were determined by comparison with a standard BSA curve ( 0 to $64 \mathrm{mg} / \mathrm{mL}$ of BSA in reconstituted powdered milk).

\section{Evaluation of Milk NAGase Activity}

$N$-Acetyl- $\beta$-D-glucosaminidase activity was determined in triplicate as described by Kitchen et al. (1978). Briefly, $50 \mu \mathrm{L}$ of diluted skim milk sample or standard was mixed with $200 \mu \mathrm{L}$ of substrate ( $2 \mathrm{mM}$ 4-methylumbelliferyl- $N$-acetyl- $\beta$-D- glucosaminide in $0.25 \mathrm{M}$ sodium citrate buffer, $\mathrm{pH}$ 4.6) and incubated in the dark for 15 $\mathrm{min}$ at room temperature before adding $1.0 \mathrm{~mL}$ of stop solution (0.1 $M$ sodium carbonate, $\mathrm{pH} 10.0)$. The released 4-methylumbelliferone was measured with a fluorescence spectrometer (excitation: $365 \mathrm{~nm}$; emission: $450 \mathrm{~nm}$ ). Concentrations of the released product were determined by comparison with 4-methylumbelliferone standards $(0$ to $25 \mu M)$. One unit of NAGase activity corresponds to $1 \mu \mathrm{mol}$ of 4 -methylumbelliferone produced in $1 \mathrm{~mL}$ of milk in $1 \mathrm{~min}$.

\section{Evaluation of Milk Lactate Dehydrogenase Activity}

Milk lactate dehydrogenase (LDH) activity was measured using the Cytotox96 NonRadioactive Cytotoxicity assay kit (Promega Corporation, Madison, WI), a colorimetric assay using the conversion of tetrazolium salt into a red formazan product to quantitatively measure released LDH (Nachlas et al., 1960). To reduce the background, whey samples were diluted 1:5 in PBS with $1 \%$ BSA. Subsequently, $150 \mu \mathrm{L}$ of diluted sample or standard was mixed with $150 \mu \mathrm{L}$ of reconstituted sub- strate before being incubated for 15 min in the dark. Reactions were stopped by adding $300 \mu \mathrm{L}$ of stop solution, and centrifugation was then performed for $5 \mathrm{~min}$ at $10,000 \times g$ at room temperature in a microcentrifuge. Subsequently, $150 \mu \mathrm{L}$ of supernatant was transferred to a 96-well plate, and absorbance was measured at $492 \mathrm{~nm}$. Milk LDH content was calculated using the standard curve ( 0 to $1,000 \mathrm{U} / \mu \mathrm{L}$ ) made by diluting the $\mathrm{LDH}$ positive control supplied with the kit in PBS with $1 \%$ (wt/vol) BSA. Each sample was tested in triplicate.

\section{Evaluation of Milk Haptoglobin Content}

Milk haptoglobin (Hp) content was measured using an ELISA kit (Tridelta Development Ltd., Bray, Ireland) according to the manufacturer's instructions. Briefly, $100 \mu \mathrm{L}$ of diluted skim milk or standard of known Hp content was added to wells coated with hemoglobin. Incubation was allowed to proceed for $1 \mathrm{~h}$ at $37^{\circ} \mathrm{C}$ so that any Hp present in the wells was captured by the hemoglobin. The wells were washed 3 times with the wash buffer provided, and $100 \mu \mathrm{L}$ of a horseradish peroxidase-labeled anti-Hp monoclonal antibody was added to each well. Incubation was allowed to proceed for $1 \mathrm{~h}$ at $37^{\circ} \mathrm{C}$. After 3 washes, $100 \mu \mathrm{L}$ of tetramethylbenzidine substrate was added, and incubation was performed at room temperature for 15 min before $100 \mu \mathrm{L}$ of stop solution was added. The absorbance of each well was read at $450 \mathrm{~nm}$ using a $630-\mathrm{nm}$ value as a blank. Each sample was evaluated in duplicate, and milk Hp content was obtained using a standard curve drawn from the standards.

\section{Zymography for Milk Proteolytic Analysis}

Zymography was performed according to Raser et al. (1995) using the Mini-Protean II system from Bio-Rad. Briefly, the zymogram gels $(0.75 \mathrm{~mm})$ were made of $0.2 \%$ (wt/vol) gelatin, 10\% (wt/vol) acrylamide, and $0.32 \% \quad(\mathrm{wt} / \mathrm{vol})$ bis-acrylamide $\left(N^{\prime}, N^{\prime}\right.$-bis-methyleneacrylamide) in $375 \mathrm{mM}$ Tris-HCl buffer, $\mathrm{pH}$ 8.8. Polymerization was initiated by adding $0.4 \%$ ( $\mathrm{vol} / \mathrm{vol}$ ) ammonium persulfate (10\% solution) and $0.05 \%$ ( $\mathrm{vol} / \mathrm{vol})$ $N, N, N^{\prime}, N^{\prime}$ - tetramethylethylenediamide. Once polymerized, a stacking gel ( $4 \%$ acrylamide and $0.11 \%$ bisacrylamide in $330 \mathrm{~m} M$ Tris-HCl buffer, $\mathrm{pH}$ 6.8) with the same polymerizing agents was poured over the zymogram gel. The gels were prerun at $4^{\circ} \mathrm{C}$ for $15 \mathrm{~min}$ at $150 \mathrm{~V}$ to remove all nonpolymerized particles. Then 10 $\mu \mathrm{L}$ of skim milk was mixed with $10 \mu \mathrm{L}$ of $2 \times$ nondenaturing loading buffer (150 mM Tris-HCl, $\mathrm{pH}$ 6.8), 20\% glycerol, and $0.0004 \%$ (wt/vol) bromophenol blue before being loaded on the zymograms. Samples were run overnight at $4^{\circ} \mathrm{C}$ at $45 \mathrm{~V}$ in a running buffer composed 
of $25 \mathrm{~m} M$ Tris-base, $192 \mathrm{~m} M$ glycine, and $0.1 \%$ SDS, $\mathrm{pH}$ 8.3. The gels were run until the lower bands (6.5, $12.5,24.7 \mathrm{kDa})$ of the Kaleidoscope prestained standards had gone out of the gels. They were then removed from the casts and soaked at room temperature with gentle agitation in a solution of $2.5 \%$ Triton X-100 for 30 min to wash out the SDS and renature the proteases. Subsequently, the renaturation buffer was replaced by the developing buffer (50 $\mathrm{m} M$ Tris, $\mathrm{pH} 7.6,0.2 \mathrm{M} \mathrm{NaCl}$, $5 \mathrm{mM} \mathrm{CaCl} 2$, and $0.02 \%$ Brij-35) for $30 \mathrm{~min}$. The developing buffer was changed, and the gels were placed at $37^{\circ} \mathrm{C}$ for $10 \mathrm{~h}$ to allow the development of enzymatic activity. Finally, the zymograms were stained at room temperature for $30 \mathrm{~min}$ in a $0.5 \%$ (wt/vol) Coomassie Blue R-250 solution dissolved in $40 \%$ (vol/vol) methanol and $10 \%$ (vol/vol) acetic acid. The gels were destained several times with a solution of 50\% methanol and $40 \%$ acetic acid until clear proteolysis bands appeared over a dark blue background. The gels were then rehydrated in water for at least 30 min before being scanned. The molecular weight was calculated using molecular weight standards ranging from 30.3 to $194.6 \mathrm{kDa}$ (Kaleidoscope prestained standards).

Total proteolytic activity was calculated after videodensitometry analysis of the negative images of the gelatin zymograms. The intensity of each proteolysis band was quantified, and total proteolytic activity was obtained by adding together the optical densities measured in each lane, arbitrarily expressed as optical density units.

\section{Statistical Analysis}

The data were analyzed as repeated measurements using the MIXED procedure of SAS (SAS Institute, Cary, NC) by groups. The covariance structure used was the spatial power because of unequal time intervals. The effects of antioxidant infusion on the milk parameters were evaluated by comparing saline-infused quarters with modulator-infused quarters, whereas the effects of the LPS + modulator combination were determined by comparison with solely LPS-infused quarters. Differences among the groups were determined at each time point using the least squares means statement with the slice option of SAS. Because the values after the LPS challenge were not normally distributed, the statistical analyses of the results were performed on the $\log _{10}$-transformed values for the following parameters: SCC, LDH, NAGase, BSA, Hp, and zymography (proteolytic activity). For all the parameters studied, statistical analysis was performed according to the following model:

$$
Y_{i j k}=\mu+C_{i}+M_{j}+T_{k}+\left(M T_{j k}\right)+\varepsilon_{i j k}
$$

In this model, $Y_{i j k}$ is the studied variable, $\mu$ is the overall mean, $C_{i}$ is the random cow effect, $M_{j}$ is the fixed effect of the modulator (DFO, GEE, or catechin), $T_{k}$ is the time fixed effect, and $e_{i j k}$ is the residual error. The effects were considered to be significant at $P \leq 0.05$ and to tend to be significant at $0.05<P \leq 0.10$.

\section{RESULTS}

Intramammary infusion of LPS resulted in the expected inflammatory reactions, as measured by standard diagnostic markers of mastitis. For all cows, intramammary infusion of LPS caused a significant increase in rectal temperature (from $38.0 \pm 0.1^{\circ} \mathrm{C}$ to $40.7 \pm 0.1^{\circ} \mathrm{C}$; $P<0.001$ ) within $6 \mathrm{~h}$. Additionally, all quarters injected with LPS developed mastitis, as indicated by the existence of udder inflammation symptoms (swelling and redness), whereas quarters infused with saline or a modulator remained normal. Two cows in the catechin group suffered from severe acute mastitis throughout the duration of the trial. Endotoxin infusion also significantly reduced quarter milk production $(P<0.001$; data not shown), both in quarters that received an infusion of LPS and in quarters that did not receive an LPS infusion. Milk production tended to return to preinfusion values within $72 \mathrm{~h}$. However, 1 of the cows experiencing severe mastitis suffered from agalactia in her 2 LPS-infused quarters from 36 to $72 \mathrm{~h}$ postinfusion.

As early as $3 \mathrm{~h}$ following LPS infusion, the lactose content of the milk dropped significantly $(P<0.001$; Figure 1) and remained low throughout the duration of the trial. Although less pronounced than in the quarters that received LPS, a decrease $(P<0.001)$ in milk lactose was also observed in both saline quarters and modulator quarters. These changes were not influenced by either of the modulators. Milk $\mathrm{pH}$ and protein content increased $(P<0.001$; data not shown) following LPS infusion. With regard to lactose, similar changes were observed $(P<0.001)$ in saline and modulator quarters, but at a lower magnitude. Again, these changes were not influenced by either of the modulators.

All LPS-infused quarters exhibited a similar and significant increase in SCC $(P<0.001$; Figure 2$)$, which remained high during the duration of the experiment, with a peak at $60 \mathrm{~h}$. Intramammary injections of DFO, catechin, or GEE alone did not increase SCC $(P>0.1)$. Furthermore, the LPS-elicited PMN influx toward the mammary gland was not affected $(P>0.1)$ by catechin, DFO, or GEE (Figures 2A, 2B, and 2C, respectively).

For all the animals, concentrations of BSA increased $(P<0.001)$ in milk from LPS and LPS + modulator quarters, reaching a peak at $3 \mathrm{~h}$ postinfusion, whereas concentrations remained low in control quarters (saline and modulator), as typically demonstrated in Figure 3. 

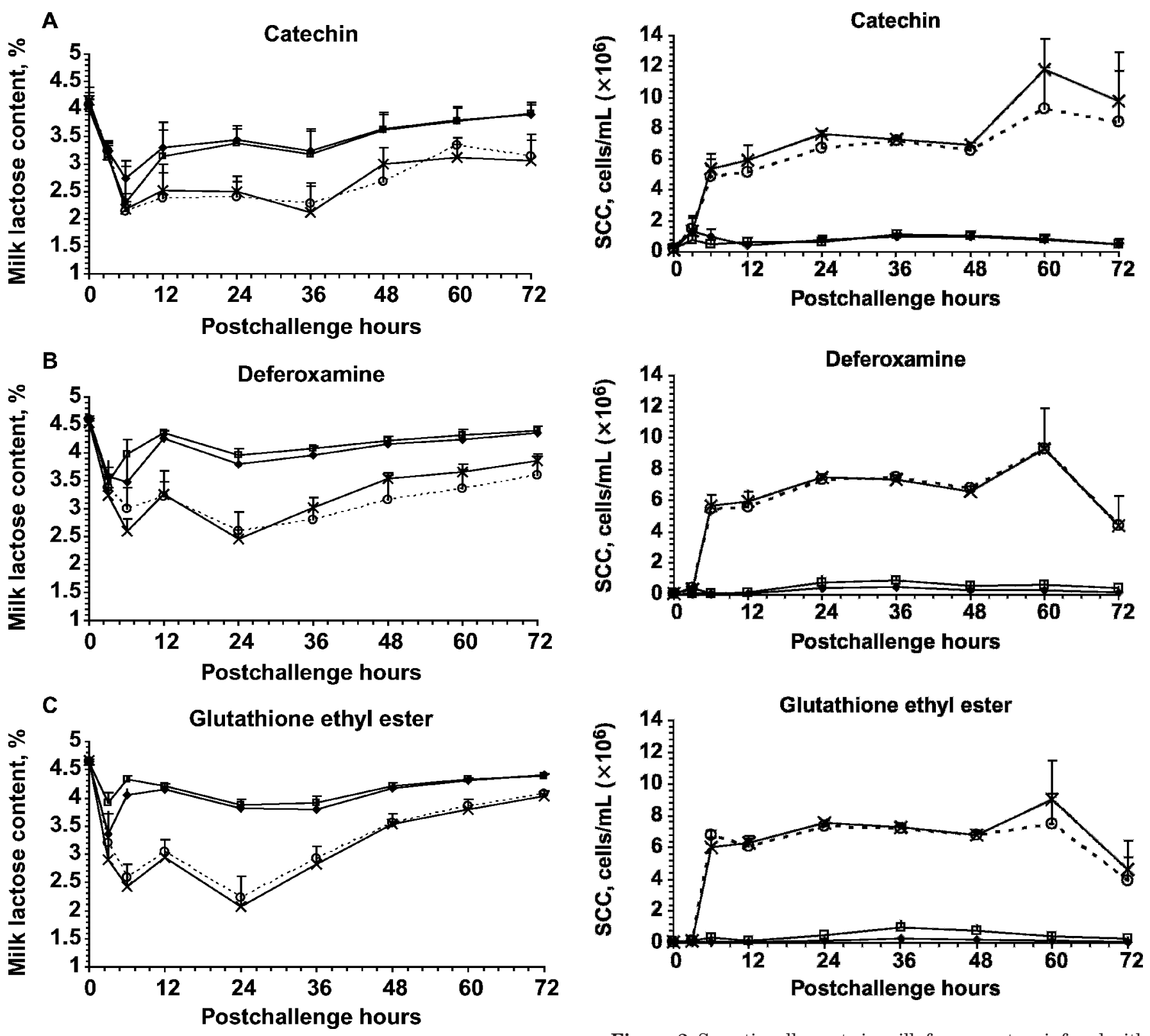

Figure 1. Milk lactose content in milk from quarters infused with saline $(\checkmark)$, modulator $(\square)$, lipopolysaccharide (LPS; $\bigcirc)$, or LPS and modulator $(X)$, where modulator corresponds to $(A)$ catechin, (B) deferoxamine, or (C) glutathione ethyl ester. The time scale refers to 0 $\mathrm{h}$ as the time of intramammary infusions. Data are presented as unadjusted means \pm SEM.

Intramammary injections of DFO (Figure 3), catechin (not shown), or GEE (not shown) alone did not increase BSA concentrations $(P>0.1)$. Additionally, levels of BSA in milk originating from LPS-infused quarters were not modified $(P>0.1)$ by infusion of DFO (Figure 3 ), catechin (not shown), or GEE (not shown).

$N$-acetyl- $\beta$-D-glucosaminidase and LDH activities increased $(P<0.001)$ in milk from all LPS and LPS +

Figure 2. Somatic cell counts in milk from quarters infused with saline $(\bullet)$, modulator ( $\square$ ), lipopolysaccharide (LPS; O), or LPS and modulator ( $\times$ ), where modulator corresponds to (A) catechin, (B) deferoxamine, or (C) glutathione ethyl ester. The time scale refers to 0 $\mathrm{h}$ as the time of intramammary infusions. Data are presented as unadjusted means \pm SEM.

modulator quarters, whereas these activities remained low in saline and modulator quarters, as represented in Figure 4. For both parameters, a peak of activity was reached at $36 \mathrm{~h}$ after LPS injection, before a gradual decline occurred. Intramammary injections of GEE or catechin did not result in lower levels of LDH or NAGase activity when compared with LPS $(P>0.1$; Figures $4 \mathrm{~A}$ and $4 \mathrm{C})$. Interestingly, injections of DFO into LPSinfused quarters resulted in a decrease $(P<0.05)$ in 


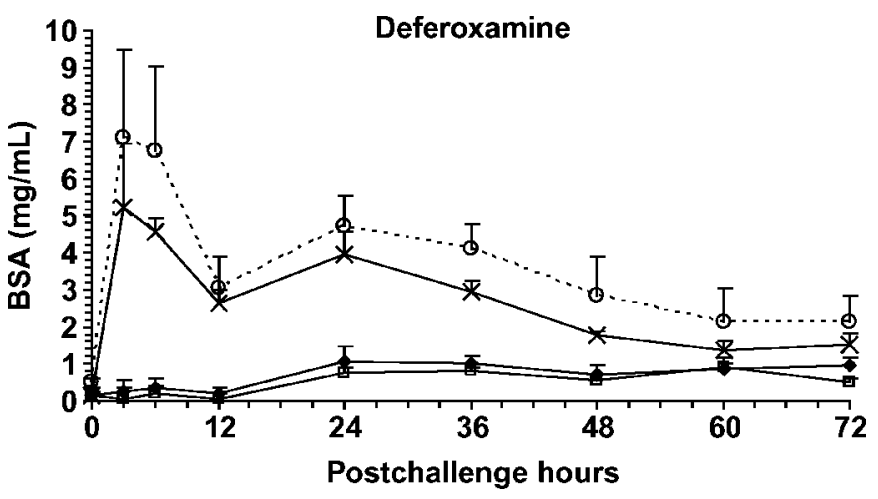

Figure 3. Concentration of BSA in milk from quarters infused with saline ( $\diamond$ ), deferoxamine $(\square)$, lipopolysaccharide (LPS; O), or LPS and deferoxamine $(x)$. The time scale refers to $0 \mathrm{~h}$ as the time of intramammary infusions. Data are presented as unadjusted means \pm SEM.

milk NAGase activity at PCH 36, whereas a trend (Figure $4 \mathrm{~B} ; P=0.07$ ) was observed at $\mathrm{PCH} 48$. Additionally, milk from LPS + DFO-infused quarters exhibited lower LDH activity than milk from LPS-infused quarters, but the effect tended to be significant only at PCH $36(P=$ $0.1)$ and $48(P=0.1$; Figure $4 \mathrm{~B})$.

In our study, the use of a highly sensitive ELISA allowed us to detect $\mathrm{Hp}$ levels as low as $300 \mathrm{ng} / \mathrm{mL}$. Milk Hp started to increase sharply at PCH 12 and peaked at PCH 36 (Figure 5). Haptoglobin content started to decline at $\mathrm{PCH} 48$ in quarters infused with LPS + DFO and at PCH 60 in LPS-infused quarters. Overall, Hp content of milk from LPS + DFO-infused quarters was lower than that of milk from LPS-infused quarters, but the effect tended to be significant only at PCH 48 (Figure 5; $P=0.08$ ).

The proteolytic activity of mastitic milk produced 3 different bands on gelatin zymograms. Bands were typically found at 72,92 , and $120 \mathrm{kDa}$ (not shown). Milk from nonchallenged quarters (saline or modulator) expressed only low levels of gelatinolytic activity. The kinetics of milk proteolysis capacity on gelatin zymograms showed that, in LPS-challenged quarters, proteolytic activity increased $(P<0.05$; Figure 6$)$ as early as $3 \mathrm{~h}$ following LPS infusion, remaining high during the entire sampling period. None of the antioxidants that were tested significantly influenced total proteolytic activity $(P>0.1)$.

\section{DISCUSSION}

The effect of selected modulators on mastitis markers and neutrophil-induced tissue damage was investigated. Injection of LPS caused mastitis in all challenged quarters. The response profiles for rectal temperature, clinical signs of mastitis, milk production, lactose content, and BSA leakage in milk were in agreement with previous reports (Bouchard et al., 1999; Bannerman et al., 2003). Additionally, SCC increased drastically in LPS-challenged quarters $6 \mathrm{~h}$ postinjection and remained high for at least $72 \mathrm{~h}$, whereas control quarters did not show any significant increase in somatic cells. This sharp increase is in agreement with previous studies that detected the peak concentration of SCC in early inflammation (Shuster and Harmon, 1991; Lee et al., 2003). However, these studies also reported a gradual but continual decline in SCC after $24 \mathrm{~h}$, whereas in our study SCC remained high after $12 \mathrm{~h}$ in all 3 treatment groups. This is probably because the cows were injected with a massive dose of LPS ( $500 \mu \mathrm{g}$ of LPS per quarter) in our study, whereas other studies usually worked with lower doses. Because the amount of LPS produced is directly related to the number of $E$. coli bacteria (Cross et al., 1993), our observations would match those made by Vangroenweghe et al. (2004), who reported a sustained high level of SCC for at least $72 \mathrm{~h}$ following intramammary injection of a high dose of live $E$. coli $\left(1 \times 10^{4}\right.$ to $\left.1 \times 10^{6} \mathrm{cfu}\right)$. In our study, this $500-\mu \mathrm{g}$ LPS dose was selected to ensure the highest duration and intensity of ROS production to maximize tissue damage (Mehrzad et al., 2001).

Levels of milk NAGase increased sharply $24 \mathrm{~h}$ after LPS infusion and reached values slightly higher than those reported by other investigators (Bouchard et al., 1999), suggesting that mammary cells were damaged by the LPS-elicited PMN influx into the mammary gland. This is in agreement with previous studies that reported a high production of ROS and pro-ROS cytokines throughout $\mathrm{d} 1$ of endotoxin mastitis (Hagiwara et al., 2001; Mehrzad et al., 2001); this production could potentially boost mammary tissue damage. Reports regarding the usefulness of NAGase as an indicator of tissue damage are controversial. Although some studies have demonstrated that the major source of milk NAGase is the mammary epithelial cells (Kitchen et al., 1978; Fox et al., 1988), some have suggested that neutrophils can contribute up to $22 \%$ of the amount of NAGase that is detected (Capuco et al., 1986). Therefore, NAGase alone cannot be used as the sole indicator of tissue damage. Nevertheless, LDH measured in milk was also higher following LPS infusion in our study. The elevated level of LDH in mastitic milk was previously found to originate mainly from damaged parenchyma cells of the udder (Bogin et al., 1977). Accordingly, we found no increase in LDH activity with our in vitro model (Lauzon et al., 2005) when PMN were activated in the absence of epithelial cells.

The use of acute phase proteins such as Hp as markers for the diagnosis of mastitis has been suggested 
Milk Lactate Dehydrogenase Activity

A

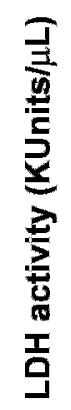

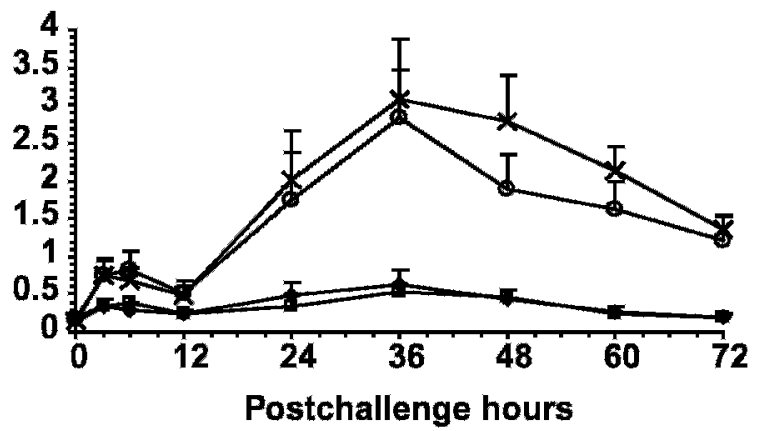

B

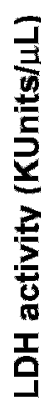

Deferoxamine

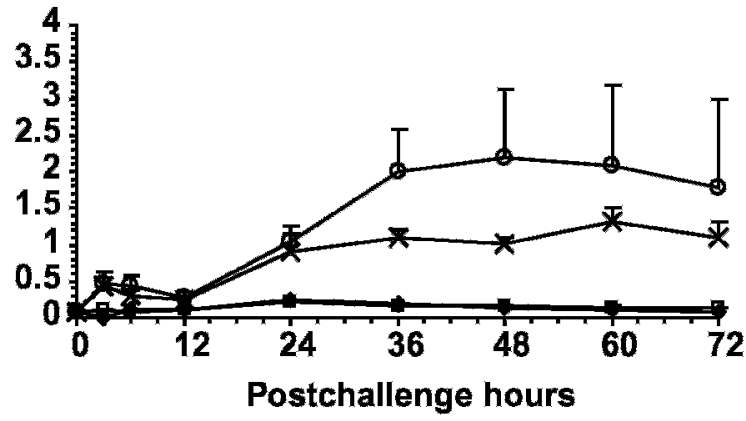

C

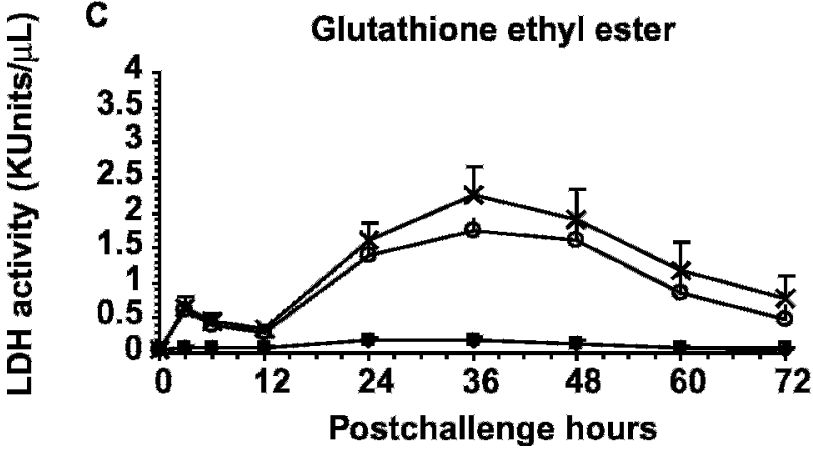

Milk NAGase Activity

A

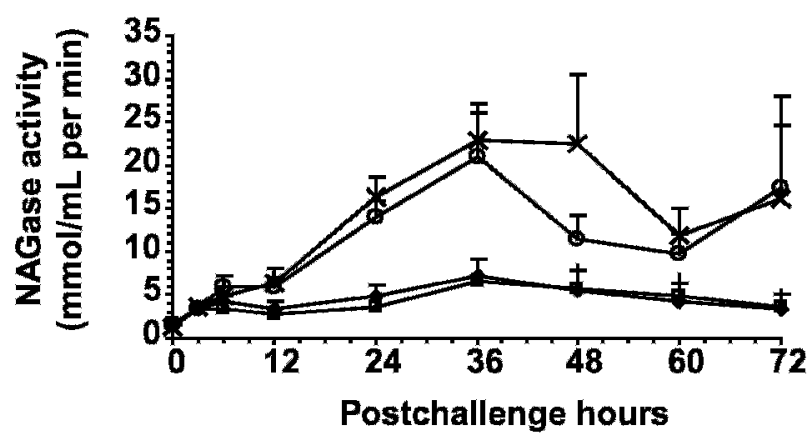

B

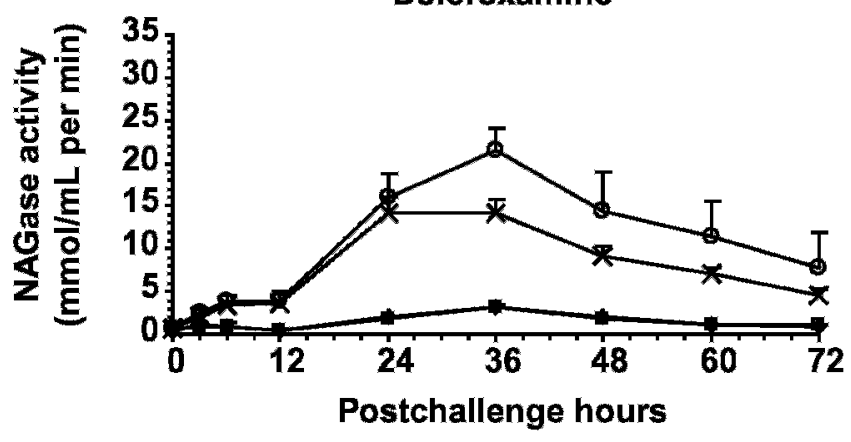

C

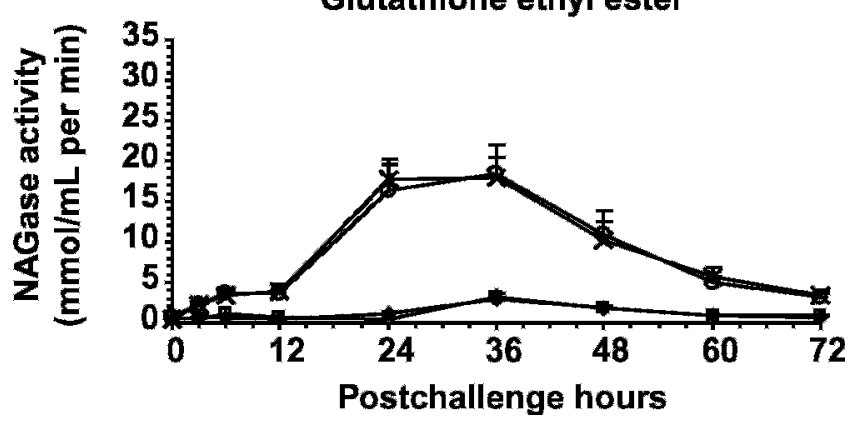

Figure 4. Activity of lactate dehydrogenase (LDH; left) or NAGase (right) in milk from quarters infused with saline ( $\bullet$ ), modulator ( $\square$ ), lipopolysaccharide (LPS; $\bigcirc$ ), or LPS and modulator $(\times)$, where modulator corresponds to (A) catechin, (B) deferoxamine, or (C) glutathione ethyl ester. The time scale refers to $0 \mathrm{~h}$ as the time of intramammary infusions. Data are presented as unadjusted means \pm SEM. Protective effect of the modulator $* P<0.05, \uparrow P<0.1$.

previously (Eckersall et al., 2001). In bovines, concentrations of acute phase proteins correlate well with the severity of an infection and with tissue damage (Nielsen et al., 2004). In our study, levels of milk Hp started to increase as early as $3 \mathrm{~h}$ after LPS infusion, reaching maximal levels near $180 \mu \mathrm{g} / \mathrm{mL}$. These results are in agreement with previous findings (Hiss et al., 2004). Our results also showed that maximal Hp concentrations were reached between 24 and $48 \mathrm{~h}$ after LPS infusion. However, the only study to report milk $\mathrm{Hp}$ levels before and after intramammary infusion of LPS did not measure milk concentrations of $\mathrm{Hp}$ at time points above $12 \mathrm{~h}$ postinfusion (Hiss et al., 2004). The high levels of $\mathrm{Hp}$ between 24 and $48 \mathrm{~h}$ paralleled our LDH and NAGase results.

Recently, Hiss et al. (2004) demonstrated that the mammary gland itself is able to synthesize $\mathrm{Hp}$, suggesting that $\mathrm{Hp}$ found in milk is not due to the increased permeability of the blood-milk barrier alone. In our study, BSA leakage reached a maximum in early inflammation; however, no drastic increase in Hp levels was detected. This finding suggests that the $\mathrm{Hp}$ found 


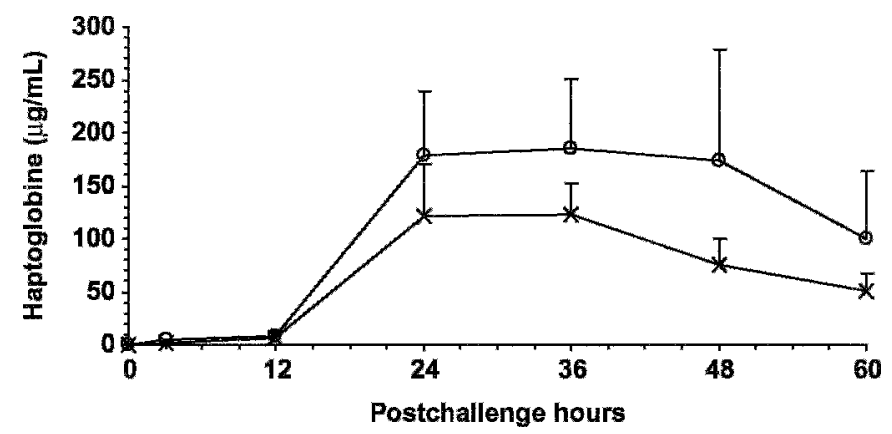

Figure 5. Concentration of haptoglobin in milk from quarters infused with lipopolysaccharides $(O)$, or lipopolysaccharides and deferoxamine $(x)$. The time scale refers to $0 \mathrm{~h}$ as the time of intramammary infusions. Data are presented as unadjusted means $\pm \mathrm{SEM}(\dagger P$ $<0.1)$.

in our milk samples was local in origin. Additionally, peak values of milk $\mathrm{Hp}$ were observed when BSA values (cows in the DFO group) were declining. Therefore, our results support the view that $\mathrm{Hp}$ is synthesized locally by the bovine mammary glands and that its presence in milk is not due to leakage of the blood-milk barrier alone, as initially suggested by Eckersall et al. (2001).

In our study, the appearance of $92-$ and $72-\mathrm{kDa}$ gelatinases in milk from LPS-infused quarters is in agreement with other in vivo studies in which an endotoxin-induced model of bovine mastitis was used (Raulo et al., 2002; Mehrzad et al., 2005). These enzymes have been identified as 2 matrix metalloproteinases (MMP), MMP-2 (72 kDa) and MMP-9 (92 kDa) (Raulo et al., 2002). Matrix metalloproteinases are generally considered to be relevant mediators of remodeling and degra-

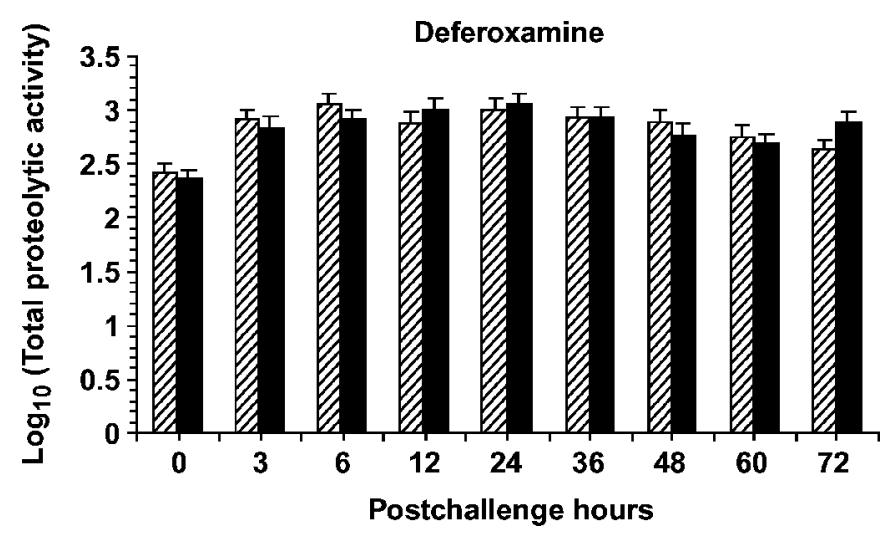

Figure 6. Total proteolytic activity in milk from quarters infused with lipopolysaccharide (hatched bars) or lipopolysaccharide and deferoxamine (solid bars). Proteolytic activity was measured from densitometric analysis of zymograms using gelatin as substrate. Time scale refers to $0 \mathrm{~h}$ as the time of intramammary infusions. Data are expressed as least-squares means of $\log _{10}$ transformed values and standard error least-squares means $<0.1$. dation of the extracellular matrix and basal membrane components (Birkedal-Hansen, 1993). They also induce tissue damage by cleaving type IV collagen (Woessner, 1991), which constitutes the backbone to which other basal membrane components are attached (Timpl, 1989). Additionally, proteases have been shown to be actively involved in udder tissue damage during mastitis. To the best of our knowledge, the $120-\mathrm{kDa}$ gelatinase has not been fully identified but was previously reported in milk during bovine mastitis (Mehrzad et al., 2005). Infusion of catechin, DFO, or GEE did not modify total proteolytic activity, since the proteolysis pattern was identical in milk from LPS-challenged quarters and milk from LPS + modulator-treated quarters at all time points. Given that proteases are mainly released by somatic cells (Mehrzad et al., 2005) and that somatic cell migration was not affected by the addition of any of the 3 modulators under assessment, it is not surprising to observe a similar pattern in all LPSchallenged quarters.

Infusion of catechin, DFO, or GEE did not affect immune cell diapedesis toward milk, as demonstrated by the low SCC and low milk BSA content in quarters infused with each modulator alone. Furthermore, for all 3 of the tested modulators, the migration of somatic cells was almost identical in milk from LPS-challenged quarters and milk from LPS + modulator-infused quarters. Additionally, for all 3 of the modulators assessed in this study, BSA levels in LPS and LPS + modulator quarters were similar, indicating that the extent of opening of the blood-milk barrier was equivalent.

Infusion of catechin, DFO, or GEE alone was not damaging to epithelial cells, as demonstrated by the low activity of LDH and NAGase (2 cytosolic enzymes) measured in milk from quarters infused with each modulator alone. These results are in agreement with our previous in vitro results using a co-culture model of bovine epithelial cells and freshly isolated bovine PMN (Lauzon et al., 2005). Additionally, infusion of catechin or GEE in LPS-challenged quarters did not decrease the levels of LDH and NAGase activity subsequently measured in milk, suggesting that these 2 modulators are not able to prevent tissue damage in the context of an acute mammary inflammation such as bovine mastitis. On the other hand, the amount of NAGase released by epithelial cells was lower in milk from LPS + DFOtreated quarters compared with milk from only LPSinfused quarters, suggesting a potential effect of DFO in preventing $\mathrm{PMN}$-induced damage. Considering that in our study there was no difference in SCC between LPS- and LPS + DFO-infused quarters, it is plausible that the difference in milk NAGase activity observed in this study between LPS and LPS + DFO quarters was due mostly to the degree of mammary cell damage. 
The amount of LDH released by epithelial cells was also lower in inflamed quarters that received DFO, suggesting a protective effect of DFO against PMN-induced damage. For both NAGase and LDH, the effects of DFO became more obvious 36 to $48 \mathrm{~h}$ after LPS infusion, which also corresponded to the point at which the release of NAGase and LDH in milk was maximal. It is thus reasonable to suggest that the release of ROS was also maximal near these time points. Consequently, the protective effects induced by DFO may become significant only when levels of ROS, and thus tissue damage, are quite high.

Our results also showed the tendency toward lower Hp in milk from LPS + DFO quarters than in milk from LPS quarters. This result is in agreement with our $\mathrm{LDH}$ and NAGase results, because the extent of tissue damage always tended to be lower in LPS + DFO-infused quarters. Furthermore, the fact that the Hp levels measured in LPS quarters is higher than those measured in LPS + DFO quarters (Figure 5) when no difference in BSA levels was observed suggests that the mechanism of regulation for $\mathrm{Hp}$ local synthesis is, at least partially, independent of the systemic response.

The use of antioxidants to prevent oxidative stress during states of several inflammation has been widely studied (Cuzzocrea et al., 2004). Several studies have reported a protective effect of catechin in different models of ROS-induced damage, such as in myocardial damage induced by ischemia-reperfusion (Aneja et al., 2004) and in LPS-induced lethality in BALB/c mice (Yang et al., 1998). Additionally, it has been reported that catechin has the ability to repress MMP-2 and MMP-9 in cancer and angiogenesis (Garbisa et al., 2001), which differs from what was observed in our study. It has recently been suggested in models of angiogenesis and pulmonary fibrosis that the principal mode of action for catechin is the inhibition of PMN recruitment, which thereby attenuates the deleterious effect caused by PMN (Donà et al., 2003; Aneja et al., 2004). As mentioned, catechin did not modify PMN influx to the mammary gland in inflamed quarters, perhaps explaining why no effect of catechin on tissue damage was observed in our study. Nevertheless, catechin did prevent PMN-induced damage in our in vitro model. It may therefore be proposed that milk is not an optimal environment for catechin to exert its anti-inflammatory effect. Indeed, a study performed by Krul et al. (2001) using an in vitro gastrointestinal model, which simulated conditions in the human digestive tract, demonstrated that the antimutagenic activity of green tea (catechin) was reduced by more than $90 \%$ when whole milk was added.

Hydrogen peroxide $\left(\mathrm{H}_{2} \mathrm{O}_{2}\right)$ is an important factor in ROS-induced tissue damage because it is a precursor of other species that have a higher reactivity (e.g., hydroxyl radicals). Additionally, $\mathrm{H}_{2} \mathrm{O}_{2}$ controls the process of inflammation by acting on the synthesis of vasoactive and chemotactic compounds (van Asbeck, 1990). Therefore, it seemed logical to evaluate the effect of GEE on PMN-induced tissue damage in our study. Glutathione (GSH) is a key component of the cellular defense cascade against injury caused by ROS (Kennedy and Lane, 1994). Indeed, GSH is the key substrate of the endogenous $\mathrm{H}_{2} \mathrm{O}_{2}$-removing enzyme GSH peroxidase, whereas reduced GEE is a cellular antioxidant that can easily cross membranes and help maintain the intracellular GSH concentration. Supplementation with GEE has been shown to prevent hyperoxia-induced mortality in newborn rats (Singhal and Jain, 2000) and to attenuate oxidant stress occurring after the exposure of bovine pulmonary artery endothelial cells to LPS (Morris et al., 1995). Additionally, using a co-culture model of activated bovine PMN and a bovine mammary epithelial cell line (MAC-T cells), we previously demonstrated in vitro that PMN-induced damage to mammary epithelial cells was prevented by the addition of GEE to the cocultures (Lauzon et al., 2005). However, no preventive effect of GEE was observed in the present study. Because GEE supplements the GSH pool, the inability of GEE to efficiently prevent tissue damage may suggest that $\mathrm{H}_{2} \mathrm{O}_{2}$ is not a major ROS involved in PMN-induced tissue damage in the mammary gland during LPS mastitis. This finding would be surprising, as $\mathrm{H}_{2} \mathrm{O}_{2}$ is known to play a central role in tissue damage induced by ROS (van Asbeck, 1990). It may therefore be reasonable to suggest that elevating the intracellular GSH concentration in mammary epithelial cells does not increase the overall ability of cells to withstand or recover from oxidative stress. This would be in agreement with a study performed by Spector et al. (1987), which reports that elevated GSH levels were deleterious to lens epithelial cells, causing a decreased ability to recover from oxidative stress.

It is generally agreed that tissue injury induced by $\mathrm{H}_{2} \mathrm{O}_{2}$ is often, if not always, dependent on the presence of a metal catalyst. Additionally, because the concentration of iron in animal tissue by far exceeds that of other transition metals, iron is considered to be the most effective catalyst for oxidative reactions such as the Haber-Weiss reaction, by which hydroxyl radicals are generated (van Asbeck, 1990). Therefore, prevention of injury caused by ROS may be achievable through the use of iron chelators to directly inhibit the generation of hydroxyl radicals. When DFO chelates free iron, it forms ferrioxamine, a very stable complex which is distributed in the extracellular space and is unable to penetrate cells (Emerit et al., 2001). Deferoxamine has been shown to be protective in various models of ROS- 
induced cellular injury, as reviewed by van Asbeck (1990). For example, it has been demonstrated that PMN-mediated injury was decreased by pretreating cultured bovine pulmonary artery endothelial cells with DFO (Gannon et al., 1987). Additionally, we also previously demonstrated in vitro that PMN-induced damage to mammary epithelial cells was prevented by the addition of DFO to the co-cultures (Lauzon et al., 2005). The results of these studies are in agreement with the results obtained in the present study, because we demonstrated that intramammary supplementation with DFO tends to prevent tissue damage, as revealed by the lower levels of milk LDH and NAGase measured in milk from LPS + DFO-treated quarters compared with levels in milk from LPS-treated quarters.

Because DFO is an iron chelator, the protective effect of DFO is most likely achieved by preventing the iron from being used in the Haber-Weiss reaction, and more specifically, in the Fenton reaction that is included in the Haber-Weiss reaction (Gutteridge et al., 1979). Additionally, hydroxyl radicals are the most noxious intermediates of oxygen reduction, because they can oxidize most organic compounds (Wrigglesworth and Baum, 1980). Consequently, the lower level of tissue damage observed in inflamed quarters treated with DFO suggests that hydroxyl radicals are specifically involved in the mammary tissue damage induced by PMN-generated ROS in cases of acute bovine mastitis.

The exact mechanism by which DFO lowered the extent of the mammary epithelial damage was not assessed in this study. In a clinical trial, Menasche et al. (1988) demonstrated that PMN exposed to DFO experienced decreased free radical production during cardiopulmonary bypass in human patients. The authors also suggest it is possible that DFO, by protecting the vascular endothelium against injury, prevents the release of inflammatory substances that prime the PMN for increased responsiveness or act as chemoattractants, or both. Varani et al. (1996) also report that DFO inhibited PMN adhesion to lung epithelial cells and vascular endothelial cells, thus preventing PMN-mediated killing of the same target cells. The authors concluded that this ability of DFO to interfere with the binding of PMN to target cells contributed to the anti-inflammatory activity attributed to DFO. Thus, in our study it is possible that the protective effect of DFO was mediated not only through iron chelation, but also through a certain local anti-inflammatory effect. Nonetheless, it appears that intramammary supplementation with DFO is not sufficient to counter all damaging effects caused by PMN. Furthermore, the use of DFO alone to prevent PMNinduced damage in the context of naturally occurring mastitis would not be an effective tool, because some bacteria such as Staph. aureus are able to use DFO as an exogenous iron source (Diarra et al., 2002). The use of another chelator of iron that remains unavailable for mastitis-causing bacteria may therefore be a more promising approach. In addition, synergistic interactions between DFO (or another chelator of iron) and other antioxidants, proteases inhibitors, or all of the above could be useful to assess in the future in order to increase the protective effect induced by intramammary infusions.

In summary, LPS-induced mastitis seems to be a good model for assessing the protective effect of different antioxidants (namely, catechin, DFO, and GEE) on PMN-induced mammary epithelial cell damage. The deleterious effects induced by ROS released by PMN in the context of LPS-induced mastitis tended to be lower in inflamed quarters infused with $\mathrm{DFO}$, as demonstrated by lower levels of LDH, NAGase, and Hp measured in milk originating from these quarters. Neither catechin nor GEE showed such protective effects. Additionally, our results suggest that DFO does not interfere with PMN function, such as migration toward the mammary gland. No effect of catechin, DFO, or GEE on PMN-released proteases was observed. We also presented results supporting the view that $\mathrm{Hp}$ is locally produced by the bovine mammary gland in response to LPS infusion. Our study also suggests that hydroxyl radicals are specifically involved in mammary tissue damage induced by PMN-generated ROS in cases of acute bovine mastitis. The use of antioxidants and iron chelators such as DFO in mastitis treatments to prevent mammary tissue damage is worth investigating, as they may aid in lowering damage to secretory cells and may thus prevent subsequent milk loss.

\section{ACKNOWLEDGMENTS}

We would like to thank L. St-James, L. Delbecchi, G. Tremblay, E. Deschênes, M. Rivest, N. Miller, J. Blouin, J. Mehrzad, and C. Prud'homme for their help and participation in sample and data collection during the animal trial. We would also like to thank all the barn staff members and especially R. St-Denis and M. Girard for taking good care of the animals.

This work was supported by NOVALAIT Inc., the Fonds Québécois de la Recherche sur la Nature et les Technologies, and the Ministère de l'Agriculture, des Pêcheries et de l'Alimentation du Québec, McGill University, and Agriculture and Agri-Food Canada.

\section{REFERENCES}

Aneja, R., P. A. Hake, T. J. Burroughs, A. G. Denenberg, H. R. Wong, and B. Zingarelli. 2004. Epigallocatechin, a green tea polyphenol, attenuates myocardial ischemia reperfusion injury in rats. Mol. Med. 10:55-62. 
Bannerman, D. D., M. J. Paape, W. R. Hare, and E. J. Sohn. 2003. Increased levels of LPS binding protein in bovine blood and milk following bacterial lipopolysaccharide challenge. J. Dairy Sci. 86:3128-3137.

Birkedal-Hansen, H. 1993. Role of cytokines and inflammatory mediators in tissue destruction. J. Periodontal Res. 28:500-510.

Bogin, E., G. Ziv, J. Avidar, B. Rivetz, S. Gordin, and A. Saran. 1977. Distribution of lactate dehydrogenase isoenzymes in normal and inflamed bovine udders and milk. Res. Vet. Sci. 22:198-200.

Borregaard, N., K. Lollike, L. Kjeldsen, H. Sengelov, L. Bastholm, M. H. Nielsen, and D. F. Bainton. 1993. Human neutrophil granules and secretory vesicles. Eur. J. Haematol. 51:187-198.

Bouchard, L., S. Blais, C. Desrosiers, X. Zhao, and P. Lacasse. 1999. Nitric oxide production during endotoxin-induced mastitis in the cow. J. Dairy Sci. 82:2574-2581.

Boulanger, V., X. Zhao, and P. Lacasse. 2002. Protective effect of melatonin and catalase in bovine neutrophil-induced model of mammary cell damage. J. Dairy Sci. 85:562-569.

Brinkmann, V., U. Reichard, C. Goosmann, B. Fauler, Y. Uhlemann, D. S. Weiss, Y. Weinrauch, and A. Zychlinsky. 2004. Neutrophil extracellular traps kill bacteria. Science 303:1532-1535.

Capuco, A. V., M. J. Paape, and S. C. Nickerson. 1986. In vitro study of polymorphonuclear leukocyte damage to mammary tissue of lactating cows. Am. J. Vet. Res. 47:663-668.

Cross, A. S., S. M. Opal, J. C. Sadoff, and P. Gemski. 1993. Choice of bacteria in animal models of sepsis. Infect. Immun. 61:2741-2747.

Cuzzocrea, S., C. Thiemermann, and D. Salvemini. 2004. Potential therapeutic effect of antioxidant therapy in shock and inflammation. Curr. Med. Chem. 11:1147-1162.

Diarra, M. S., D. Petitclerc, and P. Lacasse. 2002. Response of Staphylococcus aureus to exogenous iron. J. Dairy Sci. 85:2141-2148.

Donà, M., I. Dell'Aica, F. Calabrese, R. Benelli, M. Morini, A. Albini, and S. Garbisa. 2003. Neutrophil restraint by green tea: Inhibition of inflammation, associated angiogenesis, and pulmonary fibrosis. J. Immunol. 170:4335-4341.

Eckersall, P. D., F. J. Young, C. McComb, C. J. Hogarth, S. Safi, A. Weber, T. McDonald, A. M. Nolan, and J. L. Fitzpatrick. 2001. Acute phase proteins in serum and milk from dairy cows with clinical mastitis. Vet. Rec. 148:35-41.

Emerit, J., C. Beaumont, and F. Trivin. 2001. Iron metabolism, free radicals, and oxidative injury. Biomed. Pharmacother. 55:333339.

Fox, L. K., D. D. Hancock, J. S. McDonald, and C. T. Gaskins. 1988 $N$-Acetyl- $\beta$-D-glucosaminidase activity in whole milk and milk fractions. J. Dairy Sci. 71:2915-2922.

Gannon, D. E., J. Varani, S. H. Phan, J. H. Ward, J. Kaplan, G. O. Till, R. H. Simon, U. S. Ryan, and P. A. Ward. 1987. Source of iron in neutrophil-mediated killing of endothelial cells. Lab. Invest. 57:37-44.

Garbisa, S., L. Sartor, S. Biggin, B. Salvato, R. Benelli, and A. Albini. 2001. Tumor gelatinases and invasion inhibited by the green tea flavanol epigallocatechin-3-gallate. Cancer 91:822-832.

Gutteridge, J. M., R. Richmond, and B. Halliwell. 1979. Inhibition of the iron-catalysed formation of hydroxyl radicals from superoxide and of lipid peroxidation by desferrioxamine. Biochem. J. 184:469-472.

Hagiwara, K., H. Yamanaka, K. Hisaeda, S. Taharaguchi, R. Kirisawa, and H. Iwai. 2001. Concentrations of IL-6 in serum and whey from healthy and mastitic cows. Vet. Res. Commun. 25:99-108.

Halliwell, B., and J. M. C. Gutteridge. 1999. Free Radicals in Biology and Medicine. 3rd ed. Oxford University Press, New York, NY.

Hiss, S., M. Mielenz, R. M. Bruckmaier, and H. Sauerwein. 2004. Haptoglobin concentrations in blood and milk after endotoxin challenge and quantification of mammary $\mathrm{Hp}$ mRNA expression. J. Dairy Sci. 87:3778-3784.

Kehrli, M. E., Jr., F. C. Schmalstieg, D. C. Anderson, M. J. Van der Maaten, B. J. Hughes, M. R. Ackermann, C. L. Wilhelmsen, G. B. Brown, M. G. Stevens, and C. A. Whetstone. 1990. Molecular definition of the bovine granulocytopathy syndrome: identification of deficiency of the Mac-1 (CD11b/CD18) glycoprotein. Am. J. Vet. Res. 51:1826-1836.
Kennedy, K. A., and N. L. Lane. 1994. Effect of in vivo hyperoxia on the glutathione system in neonatal rat lung. Exp. Lung Res. 20:73-83.

Kitchen, B. J., G. Middleton, and M. Salmon. 1978. Bovine milk $N$ acetyl- $\beta$-D-glucosaminidase and its significance in the detection of abnormal udder secretions. J. Dairy Res. 45:15-20.

Krul, C., A. Luiten-Schuite, A. Tenfelde, B. van Ommen, H. Verhagen, and R. Havenaar. 2001. Antimutagenic activity of green tea and black tea extracts studied in a dynamic in vitro gastrointestinal model. Mutat. Res. 474:71-85.

Lauzon, K., X. Zhao, A. Bouetard, L. Delbecchi, B. Paquette, and P. Lacasse. 2005. Antioxidants to prevent bovine neutrophil-induced mammary epithelial cell damage. J. Dairy Sci. 88:4295-4303.

Ledbetter, T. K., M. J. Paape, and L. W. Douglass. 2001. Cytotoxic effects of peroxynitrite, polymorphonuclear neutrophils, free-radical scavengers, inhibitors of myeloperoxidase, and inhibitors of nitric oxide synthase on bovine mammary secretory epithelial cells. Am. J. Vet. Res. 62:286-293.

Lee, J.-W., M. J. Paape, T. H. Elsasser, and X. Zhao. 2003. Elevated milk soluble CD14 in bovine mammary glands challenged with Escherichia coli lipopolysaccharide. J. Dairy Sci. 86:2382-2389.

Mehrzad, J., H. Dosogne, E. Meyer, and C. Burvenich. 2001. Local and systemic effects of endotoxin mastitis on the chemiluminescence of milk and blood neutrophils in dairy cows. Vet. Res. 32:131-144.

Mehrzad, J., C. Desrosiers, K. Lauzon, G. Robitaille, X. Zhao, and P. Lacasse. 2005. Proteases involved in mammary tissue damage during endotoxin-induced mastitis in dairy cows. J. Dairy Sci. 88:211-222.

Menasche, P., C. Pasquier, S. Bellucci, P. Lorente, P. Jaillon, and A. Piwnica. 1988. Deferoxamine reduces neutrophil-mediated free radical production during cardiopulmonary bypass in man. J. Thorac. Cardiovasc. Surg. 96:582-589.

Morris, P. E., A. P. Wheeler, B. O. Meyrick, and G. R. Bernard. 1995. Escherichia coli endotoxin-mediated endothelial injury is modulated by glutathione ethyl ester. J. Infect. Dis. 172:11191122 .

Nachlas, M. M., S. I. Margulies, J. D. Goldberg, and A. M. Seligman. 1960. The determination of lactic dehydrogenase with a tetrazolium salt. Anal. Biochem. 10:317-326.

Nielsen, B. H., S. Jacobsen, P. H. Andersen, T. A. Niewold, and P. M. Heegaard. 2004. Acute phase protein concentrations in serum and milk from healthy cows, cows with clinical mastitis and cows with extramammary inflammatory conditions. Vet. Rec. 154:361-365

Oliver, S. P., and L. F. Calvinho. 1995. Influence of inflammation on mammary gland metabolism and milk composition. J. Anim. Sci. 73(Suppl. 2):18-33.

Paape, M. J., K. Shafer-Weaver, A. V. Capuco, K. Van Oostveldt, and C. Burvenich. 2000. Immune surveillance of mammary tissue by phagocytic cells. Adv. Exp. Med. Biol. 480:259-277.

Raser, K. J., A. Posner, and K. K. Wang. 1995. Casein zymography: A method to study mucalpain, m-calpain, and their inhibitory agents. Arch. Biochem. Biophys. 319:211-216.

Raulo, S. M., T. Sorsa, T. Tervahartiala, T. Latvanen, E. Pirila, J. Hirvonen, and P. Maisi. 2002. Increase in milk metalloproteinase activity and vascular permeability in bovine endotoxin-induced and naturally occurring Escherichia coli mastitis. Vet. Immunol. Immunopathol. 85:137-145.

Richter-Landsberg, C., and U. Vollgraf. 1998. Mode of cell injury and death after hydrogen peroxide exposure in cultured oligodendroglia cells. Exp. Cell Res. 244:218-229.

Schalm, O. W., J. Lasmanis, and N. C. Jain. 1976. Conversion of chronic staphylococcal mastitis to acute gangrenous mastitis after neutropenia in blood and bone marrow produced by an equine anti-bovine leukocyte serum. Am. J. Vet. Res. 37:885-890.

Shuster, D. E., and R. J. Harmon. 1991. Lactating cows become partially refractory to frequent intramammary endotoxin infusions: Recovery of milk yield despite a persistently high somatic cell count. Res. Vet. Sci. 51:272-277. 
Shuster, D. E., E. K. Lee, and M. E. Kehrli, Jr. 1996. Bacterial growth, inflammatory cytokine production, and neutrophil recruitment during coliform mastitis in cows within ten days after calving, compared with cows at midlactation. Am. J. Vet. Res. 57:15691576.

Singhal, R. K., and A. Jain. 2000. Glutathione ethyl ester supplementation prevents mortality in newborn rats exposed to hyperoxia. Biol. Neonate 77:261-266.

Spector, A., R. R. Huang, G. M. Wang, C. Schmidt, G. Z. Yan, and S. Chifflet. 1987. Does elevated glutathione protect from $\mathrm{H}_{2} \mathrm{O}_{2}$ insult? Exp. Eye Res. 45:453-465.

Timpl, R. 1989. Structure and biological activity of basement membrane proteins. Eur. J. Biochem. 180:487-502.

van Asbeck, B. S. 1990. Oxygen toxicity: role of hydrogen peroxide and iron. Adv. Exp. Med. Biol. 264:235-246.
Vangroenweghe, F., L. Duchateau, and C. Burvenich. 2004. Moderate inflammatory reaction during experimental Escherichia coli mastitis in primiparous cows. J. Dairy Sci. 87:886-895.

Varani, J., M. K. Dame, M. Diaz, and L. Stoolman. 1996. Deferoxamine interferes with adhesive functions of activated human neutrophils. Shock 5:395-401.

Weiss, S. J. 1989. Tissue destruction by neutrophils. N. Engl. J. Med. 320:365-376.

Woessner, J. F., Jr. 1991. Matrix metalloproteinases and their inhibitors in connective tissue remodeling. FASEB J. 5:2145-2154.

Wrigglesworth, J. M., and H. Baum. 1980. The biochemical functions of iron. Pages 29-86 in Iron in Biochemistry and Medicine. Vol. 2. A. Jacobs and M. Worwood, ed. Academic Press, London, UK

Yang, F., W. J. de Villiers, C. J. McClain, and G. W. Varilek. 1998. Green tea polyphenols block endotoxin-induced tumor necrosis factor-production and lethality in a murine model. J. Nutr. 128:2334-2340. 